\title{
Article
}

\section{Conflict of roles, a conflict of ideas? The unsettled relations between care team staff and independent mental health advocates.}

Mckeown, Mick, Ridley, Julie, Newbigging, Karen, Machin, Karen, Poursanidou, Konstantina and Cruse, Kaaren

Available at http://clok.uclan.ac.uk/10622/

Mckeown, Mick ORCID: 0000-0003-0235-1923, Ridley, Julie ORCID: 0000-00020879-308X, Newbigging, Karen, Machin, Karen, Poursanidou, Konstantina and Cruse, Kaaren (2014) Conflict of roles, a conflict of ideas? The unsettled relations between care team staff and independent mental health advocates. International Journal Of Mental Health Nursing, 23 (5). pp. 398-408.

It is advisable to refer to the publisher's version if you intend to cite from the work. http://dx.doi.org/10.1111/inm.12069

For more information about UCLan's research in this area go to http://www.uclan.ac.uk/researchgroups/ and search for < name of research Group>.

For information about Research generally at UCLan please go to http://www.uclan.ac.uk/research/

All outputs in CLoK are protected by Intellectual Property Rights law, including Copyright law. Copyright, IPR and Moral Rights for the works on this site are retained by the individual authors and/or other copyright owners. Terms and conditions for use of this material are defined in the policies page. 


\title{
A conflict of roles, a conflict of ideas? The unsettled relations between care team staff and independent mental health advocates
}

Mick McKeown PhD, BA (Hons), RGN, RMN - Principal Lecturer, University of Central Lancashire Julie Ridley PhD, BA (Hons) - Senior Research Fellow, University of Central Lancashire

Karen Newbigging MA (Hons), MSc, DipPsych, PhD, C Psychol AFBPS, FRSPH - Senior Lecturer, University of Birmingham

Karen Machin MPhil, BSc (Hons) - Co-researcher, University of Central Lancashire

Konstantina Poursanidou PhD, Med, BA (Hons) - Honorary Research Associate, University of Manchester

Kaaren Cruse, BA, PGDip, Co-researcher, University of Central Lancashire

\begin{abstract}
Drawing on a national study of Independent Mental Health Advocacy we explore the social relations of independent advocacy. The study was commissioned by the Department of Health (England) and involved a case study design covering eight different geographies and service configurations, and interviews or focus groups with a total of 289 stakeholders across two phases of inquiry. This paper focuses on analysis of qualitative data relevant to the relationship between mental health care services and independent advocacy services, drawn from interviews with 214 participants in phase two of the study. Discussion of these particular findings affords insights into the working relations of independent advocacy within mental health services beset by reorganizational change and funding cuts, and increasing levels of legally sanctioned compulsion and coercion. We offer a matrix which accounts for the different types of working relationships that can arise and how these are associated with various levels of understanding of independent advocacy on the one hand, and appreciation for the value of advocacy on the other. The discussion is framed by the wider literature on advocacy and the claims by practitioners such as nurses for an advocacy role as part of their professional repertoire.
\end{abstract}

\section{Key words}

Independent advocacy, mental health, nursing, social relations of work, patient voice 


\section{Introduction}

Independent mental health advocacy is rooted in the user movement and an understanding of unequal relationships between service users and care services (Kapasi \& Silvera 2002). Definitions of advocacy emphasise seeing the world through the service user's eyes, enablement of voice, involvement in decision-making and representation of interests. Independent advocacy is, therefore, of international significance in safeguarding human rights and empowering people experiencing mental distress (World Health Organisation 2005). In a UK context, the need for independent advocacy is illustrated by concerns over care and compassion (Randall \& McKeown 2014) and treatment under the Mental Health Act. Notable nurse whistleblowing cases demonstrate that practitioners can set aside their interests and advocate for patient rights and welfare (Ahern \& McDonald 2002, Jackson \& Raftos 1997). This does not obviate a need for independent advocacy, especially considering the liberty-limiting constraints of much standard psychiatric care; circumscribed by legislation and bio-technologies bound up with governance and control (Ingleby 1985, Rose 1990), with compulsion rates steadily increasing across Europe (van der Post et al. 2013, Zinkler \& Priebe 2002). In a UK context, the 2007 reforms of the 1983 England and Wales Mental Health Act established statutory rights to independent mental health advocacy (IMHA) for those detained in hospital or subject to community based compulsory orders (Community Treatment Order or CTO).

This study of IMHA across England (Newbigging et al. 2012) highlights conceptual and practical tensions between mental health services' staff and advocates. We conclude that staff affinity for advocacy is insufficient for constructive working relations unless sufficient understanding of independent advocacy is also present. Throughout the paper we refer to the various professional care providers as 'practitioners' or 'staff'.

\section{Practitioner claims to an advocacy role}

Various professional disciplines claim an advocacy role, notably nurses (Hewitt 2002) and social workers (Dalrymple \& Boylan 2013) reflected in international regulatory frameworks (Juggessur \& Isles 2009). Nelson (1988) dates nurses' interest in advocacy to Florence Nightingale, progressing from simple intercession to more sophisticated guardianship of rights and autonomy. Numerous international authors describe nursing advocacy roles across various practice domains including critical care, palliative care, learning disability 
services, mental health, and forensic (secure) settings (Bateman 2000, Black 2011, Boyle 2005, Breeding \& de Sales 2002, Cleary 2004, 1998, Davis et al. 2003, Fourie et al. 2005, Hanks 2008, Hart et al. 1998, Hewitt 2002, MacDonald 2006, Mallik 1997, 1998, Snowball 1996, Thacker 2008, Vaartio \& Leino-Kilpi 2004, Willard 1996). Mental health nursing advocacy has been explored in relation to informed consent (Usher \& Arthur 1998) and medication adherence (Happell et al. 2002). In forensic settings, perhaps most disempowering for service users, a counter-balancing nursing advocacy contribution is seen as imperative (Holmes 2001).

Nursing's professional interest in advocacy connects with espousal of caring values and empowerment principles. Social work is similarly professionally interested in advocacy's social justice potential (Dalrymple \& Boylan 2013). For critical commentators, the potential nurse advocacy role is largely unrealised, but should be enacted as part of an intellectual and political commitment to ensure the most disadvantaged voices, subject to surveillance and control, are properly heard and their rights and dignity respected (Holmes 2001). In an Australian study of inpatient mental health settings, Cleary (2004: 56 ) found nurses articulated:

a clear personal philosophy of advocacy and attempted to structure nursing interactions to promote client autonomy and informed choice.

Nursing advocacy, however, is typically represented uncritically in terms of an interest in patient welfare and safety. Any limitations are usually seen in terms of tensions with allegiances to employer or colleagues, unfettered managerialism devoted to cost cutting, prevailing power imbalances or paternalistic medical dominance (Jenny 1979, Juggessur \& Isles 2009, Miller et al. 1983, Pullen 1995, Robinson 1985, Walsh 1985, Zomorodi \& Foley 2009); essentially reflecting compromised independence.

Despite expectations that nurses ought to advocate for patients, nursing advocacy is poorly defined, weakly legislated for, and under-researched from service users' perspectives (Juggessur \& Isles 2009). Arguably, nursing's interest in advocacy is as much about professionalization strategies as genuine emancipatory values (Bernal 1992). That said, authentic advocacy can be a risky endeavour for professionals, engendering conflict with colleagues or employers (Gates 1994, 1995, Juggessur \& Isles 2009, Mallik 1997, Martin 1998). 


\section{Independent Mental Health Advocacy}

Independent advocacy has a lengthy history predating the advent of professional psychiatric disciplines (Brandon \& Brandon 2000, Campbell 2001, Henderson \& Pochin 2001). Critique of psychiatric institutions and concern with promoting autonomy, life-choices and social inclusion for service users helped strengthen the case for advocacy, leading to forms such as citizen advocacy in the US (Wolfsenburger 1983). These initiatives spread wider afield, moving beyond challenging professional hegemony to advocate for the most disenfranchised and disempowered in society (Sang \& O'Brien 1987). In the UK, voluntary sector mental health advocacy organisations emerged in the 1980s, growing out of a burgeoning user movement and influenced by developments in the Netherlands (Campbell 2009). Connections with movement politics and groups like MIND (the UK mental health charity) and the influential Nottingham Advocacy Group (Barnes 2007, Mind 1992) ensured commitment to self-advocacy was never far from the surface (Williams \& Schoultz 1982). Despite a lack of international research into independent advocacy, one Australian study identified positive impacts upon satisfaction, aftercare attendance, risk of involuntary rehospitalization, and community tenure (Rosenman et al. 2000).

Arguably, the introduction of statutory IMHA services in England and Wales was due partially to campaigning around Mental Health Act reforms by the Mental Health Alliance (2012) or was a sop, smoothing introduction of CTOs (National Black and Minority Ethnic Mental Health Network 2007). Notwithstanding such concerns, advocates welcomed the advent of IMHA as legitimating their role with mental health professionals.

The Care Quality Commission (CQC) recently assumed responsibility for monitoring the Mental Health Act in England and Wales, and their most recent report makes sobering reading (CQC 2014). Despite identifying examples of best practice, the CQC continue to question the extent to which the positive aspirations of national mental health policy are being met; raising concern that containment and control are prioritised over care and treatment, especially in inpatient settings (see also CQC 2012).

Resource allocation in a context of austerity creates significant pressures in the system, including staff shortages on wards (Bhugra 2013, Mental Health Foundation 2013). While 
bed numbers are falling rates of compulsion are rising and the CQC $(2102,2014)$ continues to cite bed pressures as a significant problem. Examining this issue specifically, the CQC (2012) found $16 \%$ of wards operating at bed occupancy rates of $100 \%$ or over, with $2 \%$ above 120\%. The Royal College of Psychiatrists (RCP) (2011) suggest that bed occupancy over an $85 \%$ optimum is most significantly associated with detriment to quality. High levels of bed occupancy complicate understandings of increasing rates of compulsion, which may be in the process of becoming the default option for admission. For the period 2012/13 over 50, 000 people were detained under the Act, the highest figure ever. Overall levels of compulsion, including CTOs, continue to rise, increasing by $12 \%$ in the previous five years (CQC 2014). More worryingly, the CQC checked 4576 patient records in the previous inspection period and found $4 \%$ where the case for detention was unlawful (CQC, 2012). Furthermore, de facto compulsion of voluntary patients and disproportionate compulsion of black and ethnic minorities (BME) continue to feature in scrutiny of the figures (CQC 2012, 2014, see also Fernando 2013). Internationally, despite a policy orientation away from institutional care, CTOs have been criticised for bringing compulsion into the private sphere in the absence of freely available alternatives to bio-medical treatment (O'Brien \& Kydd 2013). However we make sense of it, the absolute fact that more people than ever are subject to compulsion reinforces the rationale for providing independent advocacy.

With direct relevance to nursing practice, the $\operatorname{CQC}(2012,2014)$ consistently report that care plans fail to demonstrate service user involvement or evidence that compelled persons are being informed of their right to IMHA. Between the 2012 and 2014 reports the availability of IMHA rose from $85 \%$ to $92 \%$ of wards. Though the improvement is welcome this remains a deficit on mandatory requirements, and much fewer wards are ensuring regular access. For example, Kinton (2014) audited MHA commissioners and found that $30 \%$ of wards lacked information about advocacy, $22 \%$ indicated limited evidence that patients had been informed, and significant numbers were being referred only at the behest of a commissioner.

\section{Methodology}

This study was funded by the government's Department of Health Policy Research Programme. Having legislated for a statutory right to advocacy it was considered opportune to commission an evaluation of IMHA on a national scale. In phase one, a literature review (building on an earlier systematic review of mental health advocacy for African and Caribbean men (Newbigging et al. 2011)), observations of advocacy in practice and focus 
groups to define quality indicators for IMHA were undertaken. This was followed in phase two by an in-depth inquiry using a comparative case study design involving eight case study sites (large Mental Health Trusts and independent sector providers in England) chosen to exemplify different geographies, demography and service configurations; these included a variety of inpatient, community and secure settings. Full NHS ethical approval was secured. A total of 214 stakeholders, including service users, practitioner staff, managers, commissioners and advocates were interviewed in the second phase and there was also a survey of advocacy services. The findings presented here are derived from analysis of these interviews. Table 1 indicates numbers of interviewees from different stakeholder groups.

[Table 1: Study participants]

Qualitative data was subject to thematic analysis (Coffey \& Atkinson 1996). The research team comprised representation from academic, practitioner and service user perspectives, informing our interpretative framing and coding. A selected focus on the findings follows, pertaining to the relations between advocacy and mental health services. The overall findings are reported at length elsewhere (Newbigging et al. 2012, Newbigging et al. in press).

\section{The relationship between care provider staff and independent advocacy}

A range of positive and negative relationships were reported, grounded in a variety of collective and individual experiences. The advocates described working hard at developing relationships and enhancing staff knowledge of IMHA, taking care to establish trust or minimise the extent to which staff might regard advocacy as a threat. They reported some mental health settings and/or professionals being more positively predisposed to advocacy than others. The study demonstrated the extent to which both service users and professional staff appreciated effective interpersonal skills on the part of the advocates, and such skills were undoubtedly influential for quality of relationships (Newbigging et al. 2012).

\section{Channels and quality of communication}

Some communicative and feedback mechanisms were formalised via commissioning 
arrangements and were built into contracts, emphasising legal obligations. In some areas, routine meetings were convened between senior mental health service managers, advocacy service managers or advocates, care teams and service users. On the whole however, communication between advocates and ward personnel was informal. This included phone calls to ward managers to discuss the extent to which particular members of teams were welcoming of advocacy, or any problems arising on visits to wards. Advocates also made useful contributions to user involvement forums or community meetings. Advocates reported mixed experiences of communication, either direct contact with staff, being informed of changes for services users for example, or indirect consequences of other interactions:

The staff on the ward don't always communicate very well and I think that's where it breaks down ... and then you go to see the patient and you find out they've either come off the section without telling you or they've been transferred to another unit [IMHA]

Service users could be acutely conscious of such communication deficits impeding the advocate's support and, on occasion, advocacy involvement exposed shortcomings in relations between staff and service users. Grass-roots communication was not restricted to information exchange and could involve problem-solving or negotiating changes at ward level, with an interface to the more formal avenues. Some advocates were viewed by staff as unaware of appropriate channels of communication.

The extent to which advocates were involved in key meetings, as vehicles for liaison and communication varied. This reflected professionals' willingness to accommodate advocates and the limited capacity of advocates to attend meetings in addition to case-work demands. Interpersonal qualities and skills in forming relationships were important, and when relations were strained staff could quickly personalise matters:

I don't find them (advocates) the easiest people to deal with, am I allowed to say that? ... they're quite demanding. I think they expect their needs to be met straight away. [Practice Development Nurse]

Other staff, however, highlighted constructive relations with advocates, knowing them by name, with knowledge of each other's roles improving with frequency of contact. Effective working relations were associated with the extent to which staff were available for the advocates to ask questions, talk about issues, or respond to e-mail. Conversely, some staff, 
in circumstances where there were several advocacy providers, reported difficulties dealing with different advocates every time a patient needed one.

There were some difficulties locating the right member of staff at times, though work pressures were understood to be influential:

The biggest difficulty is getting hold of people when we are working with a client, you need to get information from them ... it's not that it's intentional, it's obviously they are very busy $[\mathrm{IMHA}]$

\section{Practical facilitation of advocacy}

Practical support for advocacy included making space on the ward for advocates to meet with service users, and considering the safety of the advocate; such as communicating basic information about well-being or risk prior to meetings. Some advocates were issued personal alarms or attended lone working training, but there could still be challenges:

We always make an appointment in advance ... but quite frequently they'll say... I'm sorry we haven't got a private area for you to interview the person in', so you're a bit at their mercy, but to be fair ... they're short staffed [IMHA]

Paternalistic staff felt advocacy contact early on in an admission, if a person was acutely unwell, was a waste of time or might exacerbate problems. The organisation of review meetings could be a litmus test of the health of working relationships. Arrangements for booking meetings could overlook the advocate's availability, or the agreed time of a review meeting might not be communicated to the advocate.

Advocates and mental health service staff played a role in promoting advocacy, making sure service users and staff understood how to contact the IMHA service, and that staff within the organisation had sufficient knowledge of advocacy and their related statutory duties.

Programmes of training and induction for clinical staff could improve knowledge levels and appreciation for advocacy, but there were numerous examples where basic comprehension was lacking or training offered was cursory.

Practitioners' duties to support advocacy extended to making referrals, or ensuring that 
service users' requests to see an advocate were followed up. In some instances a lack of understanding of the role of IMHA led to inappropriate referrals. Knowledge among practitioners of IMHAs' right to access records was limited. Organisational barriers existed, and none of the host organisations routinely shared information about eligible patients with IMHA services and vice versa, making it difficult to accurately monitor access and uptake, especially for people on CTOs.

\section{Mutual understanding}

Affirmation of IMHAs depended on the extent to which advocates were seen by staff to be doing a good job, to be constructively relating to service users, or whether or not, staff were already well disposed to the idea of independent advocacy. To be challenged could be difficult for some staff, while others saw this as a good thing:

We should be challenged, we need to be challenged, we should always be challenging the system for the benefit of the patient. We need to be kept on our toes. [Approved Mental Health Practitioner (AMHP)/ social worker]

The quality of working relations was strongly linked to mutual understanding of roles:

Each understanding a bit more of each other's service and you know them (IMHAs) understanding a bit more of what constraints we're under ... So it's just that bit more understanding on both parts. [Ward manager]

Some staff felt advocates misunderstood their role and work pressures, and on occasion they resented the need to offer time to advocates. Deficits in understanding the advocacy role could also lead staff to be concerned about the extent of advocates' roles and responsibilities. Understanding of statutory requirements helped improve relationships; or a lack of understanding could worsen any mistrust:

It's a statutory right, you do need to let us know when this person is admitted, and I need to hear for myself from that person that they don't want to see me ... but l'm sure you can imagine what some of the staff think, well isn't our word good enough. [IMHA]

Staff anxieties around advocacy could be amplified by concern about complaints: 
Maybe a patient has complained about the staff and they say they are bringing in the advocate ... that can be quite unsettling ... the moment the advocate walks onto the ward you can tell that this person is a bit uncomfortable because they don't know what the patient is going to be telling the advocate about them. [Clinical Team Leader]

Conversely, staff could understand and appreciate the importance of the advocacy role:

The team actually don't have a problem with that because ... they would feel that the service users needed protecting from us because we're the ones that are imposing the sanctions. [Assertive Outreach Team Manager]

The issue of opening up care to scrutiny was relevant, as was an understanding of safeguarding roles.

\section{Collaborative working}

Multiple respondents remarked upon the extent to which advocacy input might enhance the efforts of staff by eliciting information about service users' wants and needs:

They can provide a conduit for information going both ways whereby they can allow patients obviously to express their wishes, also allow patients to understand the position they're in regarding the Act, or medication. [Psychiatrist]

This resulted in some staff framing the advocacy input as an extension of team-working, with advocates pointing out to staff how they could helpfully intervene to the benefit of individual service users especially in a context of complex cases. For these staff, the advocate occupied a sort of hinterland: not one of the team, but very helpful for the team:

Ultimately we're all working for the patient's safety, wellbeing and quality of life ... albeit the advocate's independent, it shouldn't be against each other because we're all of us supposed to be focusing on the same thing. [Psychiatrist]

Similarly, the advocate's contribution could help lessen practitioner workload, with more leverage to address issues when staff struggled to effect change: 
Staff realise that they can be helped too by some of our legitimate criticisms and complaints to the middle management because sometimes when qualified staff make these ... it goes nowhere, whereas with the advocate you know they have to ... take note. [Service User]

Staff and advocates also reported working in partnership to develop specific service improvements or user involvement initiatives.

\section{Boundaries and Independence}

Attention to boundaries and maintaining independence was important, with a balance to be struck in the closeness of relationships:

We will not spend too much time in the office with [staff] because we are conscious that it is like a goldfish bowl and the patients will look in and see us talking to them and they will misconstrue that ... The patients will assume that we're talking about them individually. [IMHA]

Conversely, a lack of contact with staff could be detrimental to advocacy effectiveness and service users recognised the need for advocates to relate to care teams. Knowledgeable staff recognised the value of maintaining independence. Questions arose over the extent to which valued close working relationships might become too enmeshed, against the principles of advocacy. In the extreme, advocacy could be co-opted, fulfilling aspects of the care-team role. There was a fine line between advocating for individual's wishes and merely mollifying service users' disappointments:

So if somebody was asking for a rehabilitation trip, the advocates would know the policy and that it's highly unlikely that they're going to get one, so they're already probably preparing the patient for that outcome... So I think they just raise the issues for a debate, but quite often they know ... what's going to be possible and not possible. [Psychiatrist]

On occasion, practitioners queried the advocate's objectivity: 
I sometimes question her independence because she knows us so well ... it works for us but ... as lovely as she is, I think l'd be a lot clearer on what the patient's view was and would be a lot more questioning. [AMHP/Social worker]

Where boundaries were more tightly drawn, efforts to maintain a healthy degree of distance in relationships were acknowledged, though this could cause staff to doubt the relational skills of the advocate or feel slighted.

Some staff thought advocates lacked sufficient knowledge about clinical issues, or did not appreciate what was in the person's best interests, pushing for unrealistic demands. Other staff recognised this was not contrary to the advocacy role, with individual's wishes not always in line with clinicians' views of best interest:

We are all professional enough to be able to work collaboratively without having the same opinions ... my opinions of what's best for my patients might be very different to those of my patients. [CPN]

This sense that practitioners and advocates saw things differently because they have different roles could become wrapped up in staff reflections that privileged risk management. Especially in secure services, this could result in advocates engaging in discussions and debate with care teams regarding the merits of positive risk taking versus risk aversion in decision making.

Some staff were discomforted by IMHA because they saw themselves as having close and trusted relationships with service users and claimed advocacy as an integral part of the nursing role.

\section{Resistance and conflict}

IMHAs had experienced resistance, and had a sense that some ward staff saw them as interfering. Tensions in the relationship could lead to lip service being paid to advocacy:

There is this 'us and them', they're there to challenge us, they're there to cause problems, they're there to trip us up ... you do get that sort of sense that you're under attack and so ... you're on your guard... and if the nursing staff are feeling 
uncomfortable about people, they're not going to push it, you know they'll go through the form and tick the boxes. [Ward Manager]

The nature of the nursing role in contemporary mental health services placed them in the front line of criticism, increasing their sensitivity:

[Nurses] have to do the unpleasant stuff. So you do develop this sort of mentality, a siege mentality that you're under attack, everything is your fault ... because that's how you're used to working. [Ward Manager]

In the extreme, IMHAs were an irritant to practitioners:

The advocate has gone through the list of the patient's grievances so to speak in quite an abrupt manner. And l've said 'yes we sorted that yesterday, yes they're getting that tomorrow,' ...l suppose in a way l've resented the implication that we haven't addressed those issues. [Practice Development Nurse]

Similarly staff might question the advocate's professionalism:

They're a bloody nuisance! ... they're amateurs meddling. [AMHP/Social worker].

Service users also described staff antipathy towards advocates:

Oh they hate them with a vengeance ... Because they think that the advocate is out to get them personally, and that's just, that's not true at all you know. [Service User]

Some complete rifts in relations were reported, the effect of which was to dilute people's access to their rights. When relations broke down there was a sense of taking sides, and clearly the notion of independence was crucial to resolving some of these fractures. Staff could perceive advocacy interventions as slights on their professionalism:

\section{A working relations matrix}


We offer a matrix that represents key elements from our findings relating to the reported working relations between staff and advocates. Each quadrant accounts for the relative influence of staff disposition towards advocacy or their understanding of advocacy.

Positioning on the positivity-hostility axis was influenced by prior experiences of advocacy for some. Antagonistic standpoints suggest previously reported suspicion and hostility from professional disciplines towards the empowerment potential of advocacy (Gamble 1999, Tyrer 1989) may persist. Interestingly, a previous negative experience of advocacy did not necessarily predict aversion to advocacy; efforts to model good practice and increase staff understanding of the role could turn around negative attitudes over time.

[Figure 1: Working Relationships Matrix]

Clearly, optimal working relationships are defined and located in the top right-hand quadrant of the matrix. All of the other possibilities in some sense indicate less effective relationships between staff and advocates. For instance, in the 'enmeshed' state the clinical staff appreciate advocacy while failing to adequately understand the importance of independence Conflictual and distant working relations are associated with antipathy towards the idea of independent advocacy, but are distinguished by relative degrees of understanding of the role. It is much easier to lapse into conflict if staff do not comprehend the nature of advocacy, and at the same time have strong views that advocates interfere with patient 'best interest'.

\section{Discussion}

The qualitative findings reported here furnish a rich and detailed description of the working relations of IMHA services in the context of a case study design. As such, it is not possible to confirm how representative the data are of the national picture or how generalizable the findings may be, including across international jurisdictions. The extent of the detail and diversity of the selected sites, however, does inspire some degree of confidence that the most salient issues are covered. The participant profile is somewhat lacking in numbers of older service users and carers, suggesting further research is required to more fully elicit views from these perspectives. 
Mental health services have a key role to play in determining the quality of advocacy. Mutual understanding and appreciation of each other's roles are fundamental, and facilitate the right to access independent advocacy. Conversely, this is impeded by staff confusion over notions of independence and best interest, with uncertainties around the boundaries between IMHA and the sort of advocacy they themselves might provide. Confusion about independence has been a feature of critical commentary on the limits of nurses or other professionals acting in an advocacy role (Hewitt 2002, Juggessur \& Isles 2009). Some mental health services staff, however, felt that advocates can be relatively ignorant about mental health issues and that this is an impediment to effective advocacy. Our findings suggest that even the most knowledgeable staff, those who were well disposed to advocacy with constructive working relationships, were nonetheless, often in the dark about their statutory obligations, especially in terms of advocates' access to records.

The types of working relations identified were also associated with the emotional character of people's work. Strong emotions can arise, ranging from frustration or anger with the seeming intrusion of advocacy, or upset because service users may seek out advocates to pursue issues felt to be within the compass of the staff (McKeown et al. 2002). Conversely, Harrison and Davis (2009) argue that some of the reported under-use of independent advocacy might be because patients choose to rely upon trusted staff rather than advocates to take up concerns. This might suggest that further work is needed to promote the value of independent advocacy amongst those subject to compulsion, reinforcing recommendations of monitoring agencies (CQC 2014).

There is broad consensus around the need for a positive working culture between advocates and mental health services. Grass-roots relations will be worked out largely on the basis of whether there is mutual understanding and realistic expectations of each other's roles. Where there are positive working relationships advocacy is understood and appreciated and any challenges to staff are attended to with equanimity. On occasion, there is resistance and conflict and this can lead to complete ruptures in working relationships. Previous experiences and history of advocacy involvement with services, often predating the introduction of IMHA, can be influential in the reception afforded to advocacy. Similarly, advocacy is best facilitated within organisational cultures that espouse progressive values, and are tuned in to the human rights of service users and the limiting effects of compulsory care (Bindman et al. 2003). Appreciation of structural and contextual factors framing 
provision of IMHA are important for practitioners, senior managers and commissioners to acknowledge.

\section{Conclusion}

It is unlikely that the range of social relations reported on here are unique to the UK, as the challenge of ensuring human rights in a context of compulsion and issues in the support of independent advocacy are demonstrably widespread and have been a longstanding focus of debate on a European and an international level (Gostin 2000; Herrman et al. 2005; Jones 2005). The findings and presented conceptual matrix have a number of practical and theoretical implications. Conceptually, the matrix offers an interesting lens through which to reflect upon the social relations of advocacy practice and the extent that it is supported within services, with such considerations pivoting upon staff knowledge and affinity for independent advocacy. Practically, an obvious suggestion is for services to work cooperatively with advocates and, of course, service users, to design and deliver appropriate training for practitioners such that advocacy is better understood, its value appreciated, and its routine operation best facilitated. We are currently engaged in an implementation project that builds upon the findings of this study, including the matrix, to produce multi-media resources which could support training or service developments.

Honest and open reflections on how the advocacy relations matrix might apply to any local service arrangements and practices could provide an interesting point of departure for more deliberative discussions leading to best practice models and more harmonious working relations that appropriately ensure access to advocacy is maximised and independence is appropriately maintained. In this way, the most effective operation of advocacy services could be enabled and progress could be monitored by mapping developments back to the presented findings and configured matrix.

Acknowledgements: We would like to thank all of the service user, staff and advocacy participants in the research and other members of our research team including Laura Able, Paul Grey, Zemikael Habte-Mariam, Stephanie de la Haye, Doreen Joseph, Michelle Kiansumba and June Sadd. The research reported in this publication includes work that was commissioned and funded by the Policy Research Programme in the Department of Health. The views expressed in this publication are those of the author(s) and not necessarily those of the Department of Health. 


\section{References}

Ahern, K. \& McDonald, S. (2002) The beliefs of nurses who were involved in a whistleblowing event. Journal of Advanced Nursing, 38, 303-309.

Barnes, M. (2007) A final brick in the wall? A history of The Nottingham Advocacy Group. Available via http://studymore.org.uk/naghis.pdf accessed August 142013.

Bateman, N. (2000) Advocacy skills for health and social care professionals. London, Jessica Kingsley.

Bernal E. (1992) The nurse as patient advocate. Hastings Centre Report. 22, 18-23.

Bhugra, D. (2013) We can cure the mental health service crisis. The Guardian, Wednesday 25 September, p41.

Bindman, J., Maingay, S. \& Szmukler, G. (2003) The Human Rights Act and mental health legislation. The British Journal of Psychiatry, 182, 91-94.

Black, L. (2011) Tragedy into policy: A quantitative study of nurses' attitudes toward patient advocacy activities. American Journal of Nursing, 111, 6, 26-35.

Boyle, H. (2005) Patient advocacy in the perioperative setting. AORN Journal, 82, 2, 250 262.

Brandon, D. \& Brandon, T. (2000) The history of advocacy in mental health. Mental Health Practice, 3, 6-8. 
Breeding, J. \& de Sales, T (2002) Registered nurses' lived experience of advocacy within a critical care unit: a phenomenological study. Australian Critical Care, 15, 3, 110-117.

Campbell, P (2001) From petitions to professionals. Openmind, 107, 7.

Campbell, P (2009) The service user/survivor movement. in Reynolds, J., Muston, R., Heller, T., Leach, J., McCormick, M., Wallcraft, J. \& Walsh, M. (Eds) Mental Health Still Matters. Houndsmills, Palgrave Macmillan.

Care Quality Commission (2012) Monitoring the Mental Health Act in 2011/12. Newcastle, CQC.

Care Quality Commission (2014) Monitoring the Mental Health Act in 2012/13. Newcastle, CQC.

Cleary, M. (2004) The realities of mental health nursing in acute inpatient environments. International. Journal of Mental Health Nursing, 13, 53-60.

Coffey, A. \& Atkinson, P. (1996) Making sense of qualitative data. Thousand Oaks, CA, Sage.

Dalrymple, J. \& Boylan, J. (2013) Effective advocacy in social work. London, Sage.

Davis, A.; Konishi, E. \& Tashiro, M. (2003) A pilot study of selected Japanese Nurses' ideas on patient advocacy. Nursing Ethics, 4, 404-410. 
Fernando, S. (2013) Cultural diversity, mental health and psychiatry: the struggle against racism. London, Routledge.

Fourie, W., McDonald, S., Connor, J. \& Bartlett, S. (2005) The role of the registered nurse in an acute mental health inpatient setting in New Zealand: perceptions versus reality. International. Journal of Mental Health Nursing, 14, 134-141.

Gamble, D. (1999) The value of advocacy: putting ethics in to practice. Psychiatric Bulletin, 23, 569-570.

Gates, B. (1994) Advocacy: A Nurses' Guide. London, Scutari Press.

Gates, B. (1995) Whose best interest. Nursing Times, 25, 31-32.

Gostin, L. O. (2000) Human Rights of Persons with Mental Disabilities: The European Convention of Human Rights, International Journal of Law and Psychiatry, 23, 2, 125-159

Hanks, R. (2008) The lived experience of nursing advocacy. Nursing Ethics, 15, 4, 468- 477.

Happell, B., Manias, E. \& Pinikahana, J. (2002) The role of the inpatient mental health nurse in facilitating patient adherence to medication regimes. International Journal of Mental Health Nursing, 11, 251-259.

Harrison \& Davis, R. (2009) Advocacy: time to communicate. Advances in Psychiatric Treatment, 15, 57-64. 
Hart, G., Yates, P., Clinton, M. \& Windsor, C. (1998) Mediating conflict and control: practice challenges for nurses working in palliative care. International Journal of Nursing Studies, 35, 252-258.

Henderson, R. \& Pochin, M. (2001) A Right Result? Advocacy, justice and empowerment. Bristol, Policy Press.

Herrman, H., Saxena, S. \& Moodie, R. (Eds) (2005) Promoting mental health: concepts, emerging evidence, practice. A Report of the World Health Organization, Department of Mental Health and Substance Abuse in collaboration with the Victorian Health Promotion Foundation and The University of Melbourne. Geneva, World Health Organization.

Hewitt, J. (2002) A critical review of the arguments debating the role of the nurse advocate. Journal of Advanced Nursing, 37, 439-445.

Holmes, D. (2001) From iron gaze to nursing care: mental health nursing in the era of panopticism. Journal of Psychiatric and Mental Health Nursing, 8, 7-15.

Ingleby, D. (1985) Professionals as socialisers: The 'psy complex'. In A. Scull \& S. Spitzer (eds.) Research in Law, Deviance and Social Control 7. New York, Jai Press. pp.79-109.

Jackson, D. \& Raftos, M. (1997) In uncharted waters: Confronting the culture of silence in a residential care institution. International Journal of Nursing Practice, 3, 34-39.

Jenny, J. (1979) Patient advocacy - another role for nursing. International Nursing Review 26, 176-181.

Jones, M (2005) Can international law improve mental health? Some thoughts on the proposed convention on the rights of people with disabilities, International Journal of Law and Psychiatry, 28, 183-205 
Juggessur, T. \& Isles, I. (2009) Advocacy in mental health nursing: an integrative review of the literature. Journal of Psychiatric and Mental Health Nursing, 16, 187-195.

Kapasi, R., Silvera, M. (2002). A standards framework for delivering effective health and social care advocacy for black and minority ethnic Londoners. London, Kings Fund.

Kinton (2014). An audit of data from MHA Commissioner visits July-December 2013. Conference presentation: Personalisation at Commissioning Independent Mental health advocacy services: What does good look like? London, NCVO, February $19^{\text {th }} 2014$.

MacDonald, H. (2006) Relational ethics and advocacy in nursing: literature review. Journal of Advanced Nursing, 57, 119-126.

Mallik, M. (1997) Advocacy in nursing - a review of the literature. Journal of Advanced Nursing, 25, 130-138.

Mallik, M. (1998) Advocacy in nursing: perceptions and attitudes of the nursing elite in the United Kingdom. Journal of Advanced Nursing, 28, 1001-1011.

Martin, G. (1998) Communication breakdown or ideal speech situation: the problem of nurse advocacy. Nursing Ethics, 5, 147-157.

McKeown, M., Bingley, W., Denoul, I. (2002) A review of mental health advocacy services at the secure care services of Prestwich Hospital. UCLAN/North West Secure Commissioning Team.

Mental Health Alliance (2012) The Mental Health Act 2007: a review of its implementation. London, Mental Health Alliance.

http://www.mentalhealthalliance.org.uk/news/MHA May2012 FINAL.pdf accessed November 21st 2013. 
Miller B., Mansen T. \& Lee H. (1983) Patient advocacy: do nurses have the power and authority to act as patient advocate? Nursing Leadership, 6, 56-60.

MIND, (1992) The MIND guide to advocacy in mental health: empowerment in action. London, Mind Publications.

National Black and Minority Ethnic Mental Health Network (2007) Memorandum submitted by the National Black and Minority Ethnic Mental Health Network (MH 23). Hansard. http://www.publications.parliament.uk/pa/cm200607/cmpublic/mental/memos/uc2302.htm

Nelson, M. (1988) Advocacy in nursing. Nursing Outlook, 36, 136-141.

Newbigging, K., McKeown, M. \& French, B. (2011) Mental health advocacy and African and Caribbean men: good practice principles and organisational models for delivery. Health Expectations, DOI: 10.1111/j.1369-7625.2011.00692.x

Newbigging, K. Ridley, J., McKeown, M., Machin, K., Poursanidou, K., Able, L., Cruse, K., Grey, P., de la Haye, S., Habte-Mariam, Z., Joseph, D., Kiansumba, M. \& Sadd, J. (2012) The Right to Be Heard: Review of the Quality of Independent Mental Health Advocate (IMHA) Services in England. Research report. University of Central Lancashire, http://www.uclan.ac.uk/research/environment/projects/assets/mental health wellbeing revie $\underline{w}$ of independent mental health advocate research report 190612.pdf accessed 18.2.14

Newbigging, K., Ridley, J., McKeown, M., Machin, K. \& Poursanidou, D. (in press) "When you haven't got much of a voice": An evaluation of the quality of Independent Mental Health Advocate (IMHA) Services in England. Health \& Social Care in the Community.

O'Brien, A. \& Kydd, R. (2013). Compulsory Community Care in New Zealand Mental Health Legislation 1846-1992. SAGE Open, April-June, 1-8, DOI: 10.1177/2158244013490175 
Pullen, F. (1995) Advocacy: a specialist practitioner role. British Journal of Nursing, 4, 275278.

Randall, D. \& McKeown, M. (2014) Editorial. Failure to care: nursing in a state of liquid modernity? Journal of Clinical Nursing, 23, 766-767.

Robinson, M. (1985) Patient advocacy and the nurse: is there a conflict of interest? Nursing Forum, 22, 58-63.

Rose, N. (1990) Governing the soul: the shaping of the private self. London, Routledge.

Rosenman, S., Korten, A., \& Newman, L. E. (2000) Efficacy of continuing advocacy in involuntary treatment. Psychiatric Services, 51, 8, 1029-1033.

Royal College of Psychiatrists (2011) Do the right thing: how to judge a good ward. Ten standards for adult in-patient mental healthcare, Occasional Paper 79. London, RCP.

Sang, B. \& O'Brien, J. (1987) Advocacy: The UK and American Experience. London, King Edward Hospital Fund for London.

Snowball, J. (1996) Asking nurses about advocating for patients: "reactive" and "proactive" accounts. Journal of Advanced Nursing, 24, 67-75.

Thacker, K. (2008) Nurses' advocacy behaviours in end of life nursing care. Nursing Ethics, 15, 174-185.

The Mental Health Foundation (2013) Starting Today: the future of mental health services. Final Inquiry Report. London, The Mental Health Foundation. 
Tyrer, P. (1989) Power in Strange Places: User Empowerment in Mental Health Services. Edited by Ingrid Barker and Edward Peck. Good Practices in Mental Health, 380-384 Harrow Road, London W9 2HU.1988. Pp 30. Psychiatric Bulletin, 13, 307-308

Usher, K. \& Arthur, D. (1998) Process consent: a model for enhancing informed consent in mental health nursing. Journal of Advanced Nursing, 27, 692-697.

Vaartio, H. \& Leino-Kilpi. (2004) Nursing advocacy - a review of the empirical research 1990- 2003. International Journal of Nursing Studies, 42, 705-714.

van der Post, L., Peen, J., Visch, I., Mulder, C., Beekman, A. \& Dekker, J. (2013) Patient perspectives and the risk of compulsory admission: The Amsterdam Study of Acute Psychiatry V. International Journal of Social Psychiatry, DOI: 10.1177/0020764012470234

Walsh, P. (1985) Mental health dilemmas. Speaking up for the patient. Nursing Times, 81, 24-26.

World Health Organisation. (2005) Empowerment and mental health advocacy. World Health Organization, Geneva.

Willard, C. (1996) The nurse's role as patient advocate: obligation or imposition? Journal of Advanced Nursing, 24, 60-66.

Williams, P. \& Schoultz, B. (1982) We Can Speak for Ourselves. Human Horizons Series. Worcester, Ebenezer Baylis and Sons Ltd, Trinity Press.

Wolfensberger, W. (1983) Social role valorization: a proposed new term for the principle of normalization. Mental Retardation, 21, 234-239.

Zinkler, M. \& Priebe, S. (2002) Detention of the mentally ill in Europe - a review. Acta Psychiatrica Scandinavica, 106, 3-8. 
Zomorodi, M. \& Foley, B. (2009) The nature of advocacy vs. paternalism in nursing: clarifying the "thin line". Journal of Advanced Nursing, 65, 1746-1752. 